\title{
Effect of combined loading on the microstructure and microhardness of austenitic steel
}

\author{
M.V. Karavaeva ${ }^{1, \dagger}$, M.M. Abramova ${ }^{1}$, N.A. Enikeev ${ }^{1}$, G.I. Raab ${ }^{1}$, R.Z. Valiev ${ }^{1,2}$ \\ †karma11@mail.ru
}

${ }^{1}$ Ufa State Aviation Technical University, 12 K. Marxa St., 450000, Ufa, Russia

${ }^{2}$ Saint Petersburg University, 7/9 Universitetskaya emb., 199034, St. Petersburg, Russia

\begin{abstract}
Increasing the strength of low carbon austenitic steels, which are not hardened by quenching, is possible due to the formation of ultrafine-grained (UFG) structure during severe plastic deformation (SPD). However, the most notable hardening during SPD is observed at the initial stages of processing, after which the hardening rate decreases markedly. One of deformation parameters significantly affecting the structure is loading path. Using non-monotonic loading allows one to activate new glide systems resulting in an accelerated process of UFG structure formation and the resulting structures are characterized by high dislocation density and smaller grain sizes. In this work, non-monotonic loading by a combination of two methods, equal channel angular pressing (ECAP) and subsequent rolling with varying reduction rate, was used. It has been shown that the combination of SPD method (ECAP) and rolling leads to an additional increase in the microhardness of UFG austenitic steel. Additional hardening is associated with features of the microstructure formed under combined loading. The structure is characterized by a fine grain size and high density of dislocations compared with the structure after rolling or ECAP. It is shown that during deformation the microstructure changed from banded structure to a subrgrain-granular one. For the samples subjected to ECAP before rolling this process occurs at a less rolling strain. Furthermore, after the combined loading a noticeable volume fraction of twins in the microstructure was observed as compared to their rather small amount after ECAP. With a strain increase during rolling the rate of microhardness growth slows down.
\end{abstract}

Keywords: austenitic steel, strength, ultrafine-grained microstructure, combined loading.

\section{Влияние комбинированного нагружения на микроструктуру и микротвердость аустенитной стали}

\author{
Караваева М.В. ${ }^{1 \dagger}$, Абрамова М.М.. ${ }^{1}$ Еникеев Н.А. ${ }^{1}$, Рааб Г.И. ${ }^{1}$, Валиев Р.3. ${ }^{1,2}$ \\ ${ }^{1}$ ФГБОУ ВО Уфимский государственный авиационный технический университет, ул. К.Маркса, 12, 450000,Уфа, Россия \\ ${ }^{2}$ Санкт-Петербургский государственный университет, Университетская наб. 7-9, 199034, Санкт-Петербург, Россия
}

Повышение прочности малоуглеродистых аустенитных сталей возможно формированием ультрамелкозернистой (УМЗ) структуры в процессе интенсивной пластической деформации (ИПД). Однако при ИПД наиболее заметное упрочнение наблюдается на начальных стадиях обработки, после чего скорость упрочнения заметно снижается. Одним из деформационных параметров, значительно влияющих на структуру, является вид нагружения. В частности, немонотонное нагружение позволяет активировать новые системы скольжения, в результате чего ускоряются процессы формирования структуры, повышается плотность дислокаций и уменьшаются размеры зерен. Немонотонное нагружение может быть реализовано, например, изменением вида деформационной обработки. В работе рассмотрено влияние комбинированного нагружения в виде последовательного выполнения равноканального углового прессования (РКУП) и прокатки на микроструктуру и механические свойства аустенитной стали. Показано, что комбинация ИПД методом (РКУП) и прокатки приводит к дополнительному увеличению микротвердости УМЗ аустенитной стали. Такое упрочнение связано с особенностями микроструктуры, формируемой при комбинированном нагружении. Структура характеризуется более мелким размером зерен и повышенной плотностью дислокаций по сравнению со структурой после РКУП или прокатки. Показано, что в процессе деформирования происходит изменение полосовой микроструктуры на зёренно-субзёренную. Для образцов, подвергнутых РКУП перед прокаткой этот процесс происходит при меньшей степени прокатки. Кроме того, после комбинированного нагружения в микроструктуре наблюдается заметная объемная доля двойников, которых нет после прокатки и которые присутствуют после РКУП только в незначительном количестве. С увеличением степени деформации при прокатке темп повышения микротвердости уменьшается.

Ключевые слова: аустенитная сталь, прочность, ультрамелкозернистая микроструктура, комбинированное нагружение. 


\section{1. Введение}

Различные металлы и сплавы с ультрамелкозернистой (УМЗ) микроструктурой, полученной интенсивной пластической деформацией (ИПД), демонстрируют значительно более высокие прочностные характеристики, чем крупнозернистые сплавы. Это убедительно доказано большим количеством экспериментальных данных, полученных на разных материалах [1-4]. Однако известно, что при различных методах ИПД наиболее значительное упрочнение наблюдается на начальной стадии деформирования $[5,6]$. Например, при равноканальном угловом прессовании величина упрочнения значительно снижается уже после 1-2 проходов [5]. Получить дополнительное упрочнение сплава возможно при комбинации разных видов нагружения, другими словами, при смене напряженно-деформированного состояния. Вид нагружения оказывает влияние на кинетику микроструктурной эволюции и на однородность получаемой микроструктуры. Этот эффект используется и в методах ИПД. Например, показано, что маршрут равноканального углового прессования (РКУП) имеет большое значение при деформации $[7,8]$. Лучшие результаты с точки зрения измельчения микроструктуры и повышения механических свойств получали при использовании маршрутов $B$ и $B c$, при которых заготовка поворачивается относительно своей оси между проходами РКУП. Такой поворот меняет схемы главных напряжений и деформаций в материале, в результате чего процесс деформирования становится немонотонным. Примером немонотонного нагружения является всесторонняя ковка, при реализации которой смена схемы главных напряжений реализуется в результате поворота заготовки последовательно относительно трех осей [9, 10]. Исследования, проведенные на титановых [11], медных [12] и алюминиевых [13, 14] сплавах, показали, что сочетание РКУП с волочением или прокаткой приводит к дополнительному увеличению микротвердости и прочности УМЗ материалов. Аналогичный результат был получен для аустенитной стали: при проведении дополнительной прокатки на 77\% образцов после РКУП микротвердость и прочность стали увеличились на $35 \%$ за счет формирования более мелкозернистой микроструктуры и увеличения плотности дислокаций [15]. Для аустенитной стали повышение прочности термической обработкой практически невозможно, поэтому дополнительное упрочнение в результате холодной пластической деформации является актуальной задачей. В данной работе проведено исследование влияния степени деформации при прокатке после РКУП на микроструктуру и упрочнение аустенитной стали.

\section{2. Материал и методика эксперимента}

Материалом исследования является сталь 08X18Н10Т, химический состав которой приведен в Таблице 1.

Для получения однофазной аустенитной структуры сталь подвергли закалке в воду с температуры $1050^{\circ} \mathrm{C}$ (выдержка при температуре составила 1 час). Далее это состояние называется «Закалка».
Интенсивную пластическую деформацию прутков диаметром 10 мм длиной 100 мм осуществили методом равноканального углового прессования (РКУП) за 8 проходов при температуре $400^{\circ} \mathrm{C}$, угол пересечения каналов составил $120^{\circ}$, маршрут $B c$ [15]. Это состояние далее обозначено как «РКУП». Часть заготовок после РКУП была подвергнута исследованию микроструктуры и механических свойств на растяжение. Вторая часть заготовок направлена на прокатку.

Прокатку проводили на гладких роликах при температуре нагрева заготовки $400^{\circ} \mathrm{C}$ за несколько проходов до конечной толщины полосы 0,7 мм. Микроструктуру и свойства изучали после прокатки на общую степень деформации $e=\ln \left(h_{0} / h_{k}\right)=1,5\left(h_{0}, h_{k}-\right.$ начальная и конечная толщина полосы, соответственно) - далее это состояние называется «РКУП + Прокатка1,5», а также после прокатки на общую степень деформации $e=2,7-$ далее это состояние называется «РКУП + Прокатка2,7».

Для сравнения микроструктуру и свойства исследовали также в заготовках, подвергнутых такой же прокатке без предварительной деформации методом РКУП. Эти состояния далее называются «Прокатка 1,5» и «Прокатка 2,7».

Микроструктуру исследовали в продольном сечении прутка и полосы. Исследование структуры проводили с использованием оптического микроскопа Olympus GX51, растрового электронного микроскопа JEOL JSM-6490VL и просвечивающего электронного микроскопа JEOL JEM-2100. Размеры зерен в деформированных образцах оценивали по темнопольным изображениям структуры. Было измерено не менее 300 зерен для каждого состояния.

Микротвердость определяли на приборе Micromet-5101 в продольном направлении.

\section{3. Результаты исследования и обсуждение}

Микроструктура стали в состоянии «Закалка» представляет собой равноосные аустенитные зерна со средним размером $62 \pm 11$ мкм. Практически все зерна содержат широкие двойники (рис. 1a).

Микроструктура после РКУП (рис. 1b) характеризуется полосами сдвига с тонкими границами, в пределах которых наблюдаются широкие дислокационные границы. Эти границы разделяют полосы на неравноосные ячейки. Размеры ячеек составляют в среднем 180 нм в поперечном и 370 нм в продольном направлении (рис. 1b). В зернах присутствуют отдельные очень тонкие деформационные двойники. Доля зерен с двойниками не превышает 5\%. Среднее расстояние между двойниковыми границами составило 75 нм. Электронограмма (вставка рис. $1 b)$ представлена отдельными рефлексами, расположенными по окружности [15].

Табл. 1. Химический состав аустенитной стали.

Table 1. Chemical composition of the austenite steel.

\begin{tabular}{|c|c|c|c|c|c|c|c|}
\hline $\mathbf{C}$ & $\mathbf{C r}$ & $\mathbf{N i}$ & $\mathbf{T i}$ & $\mathbf{S i}$ & $\mathbf{S}$ & $\mathbf{P}$ & $\mathbf{F e}$ \\
\hline 0,08 & 16,19 & 9,13 & 0,3 & 0,58 & 0,03 & 0,08 & основа \\
\hline 0,08 & 16,19 & 9,13 & 0,3 & 0,58 & 0,03 & 0,08 & bаsе \\
\hline
\end{tabular}


Аналогичная структура, только с более крупными ячейками со средним размером 560 нм, наблюдается в состоянии «Прокатка 1,5» (рис. 1с, табл. 2). Двойники в этом состоянии не наблюдаются.

При увеличении степени деформации при прокатке (состояние «Прокатка 2,7») микроструктура стали значительно изменяется (рис. 1d). Полосовая структура сохраняется только в локальных областях. В структуре образца можно видеть структурные элементы, окруженные как тонкими границами, харак- терными для зеренной структуры, так и широкими неравновесными границами, более присущими субзеренной (ячеистой) структуре; как области практически свободные от дислокаций, так и области с повышенной плотностью дислокаций. Электронограмма имеет вид отдельных рефлексов, расположенных по окружности и имеющих азимутальное размытие. Поэтому структура может быть охарактеризована как равноосная зёренно-субзёренная. Средний размер субзерен/зерен составляет 490 нм.

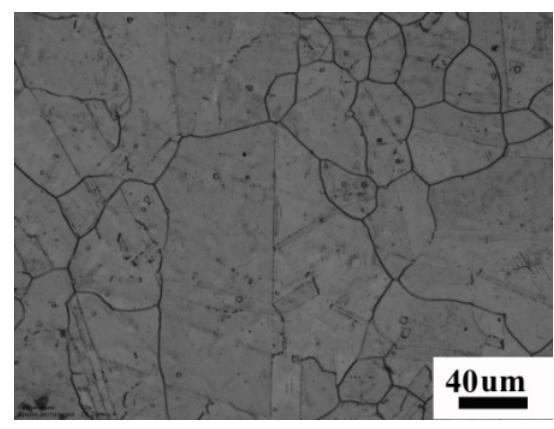

a

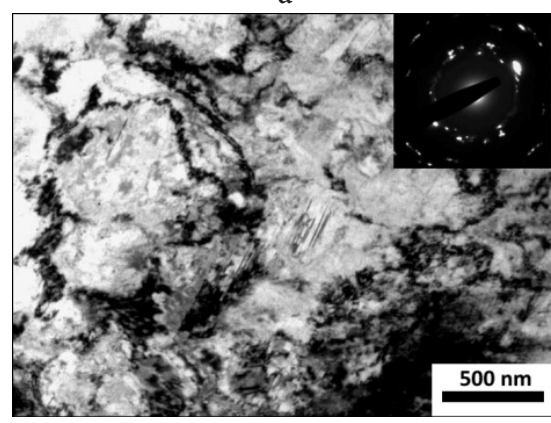

d

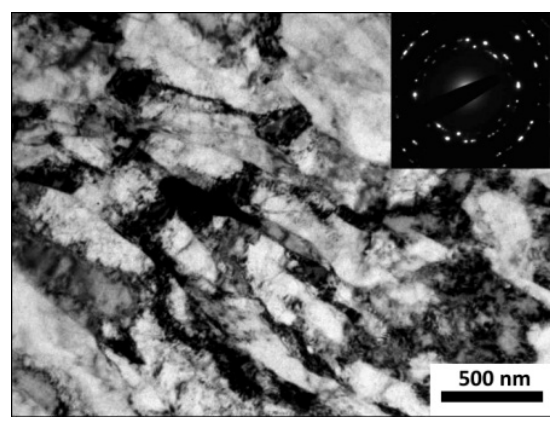

$\mathrm{b}$

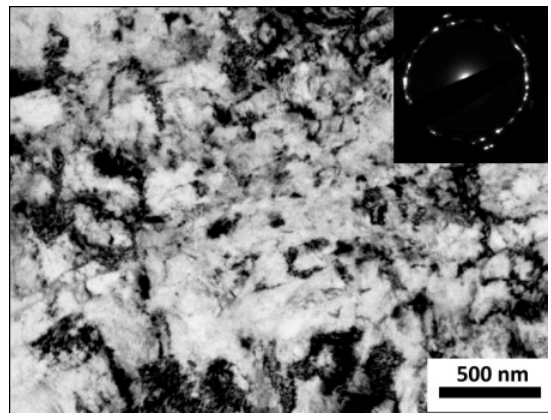

e
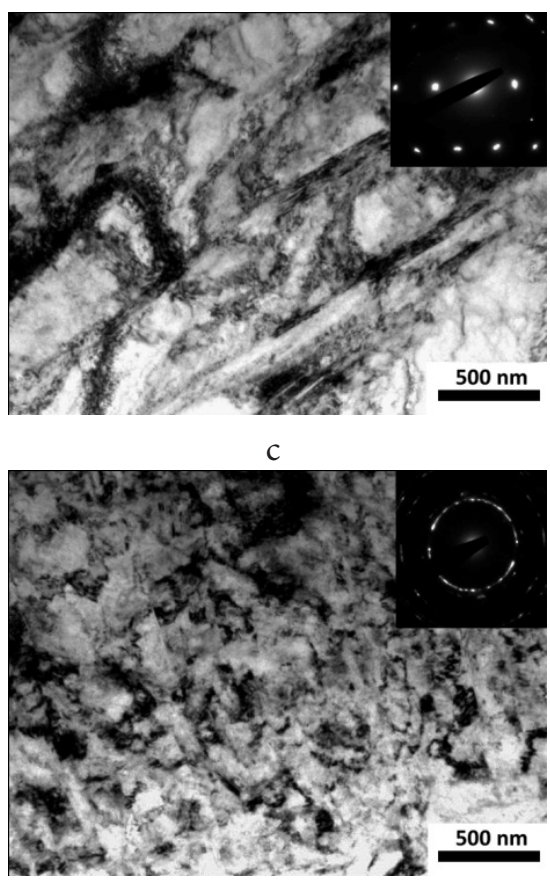

Рис. 1. Микроструктура стали после различной обработки: a - «Закалка»; b - «РКУП», с - «Прокатка 1,5», d - «Прокатка 2,7», е - «РКУП + Прокатка 1,5», f - «РКУП + Прокатка 2,7» (а - оптическая, b-f - просвечивающая микроскопия).

Fig. 1. Microstructure of the steel after different types of processing: $a-$ «uenched»; b —ECAP», c — «Rolling 1,5», d — «Rolling 2,7», $\mathrm{e}-$ - ECAP + Rolling 1,5», f - «ECAP + Rolling 2,7» (a - OM, b-f - TEM $)$.

Табл. 2. Особенности структуры стали после деформации.

Table 2. Features of the structure of steel after straining.

\begin{tabular}{|c|c|c|c|c|}
\hline $\begin{array}{l}\text { Состояние } \\
\text { Condition }\end{array}$ & $\begin{array}{c}\text { Размер структурных } \\
\text { элементов, нм } \\
\text { Grain/cell size, nm }\end{array}$ & $\begin{array}{c}\text { Доля полосовой } \\
\text { структуры, \% } \\
\text { Volume fraction } \\
\text { of banded structure, \% }\end{array}$ & $\begin{array}{c}\text { Доля зерен } \\
\text { с двойниками, \% } \\
\text { Fraction of grains } \\
\text { with twins, \% }\end{array}$ & $\begin{array}{c}\text { Средняя ширина } \\
\text { двойников, нм } \\
\text { Average twin } \\
\text { spacing, nm }\end{array}$ \\
\hline $\begin{array}{l}\text { РКУП } \\
\text { ЕСАР }\end{array}$ & 350 & 60 & 5 & 75 \\
\hline $\begin{array}{c}\text { РКУП + прокатка 1,5 } \\
\text { ECAP + Rolling 1,5 }\end{array}$ & 110 & 10 & 14 & 30 \\
\hline $\begin{array}{c}\text { РКУП + прокатка 2,7 } \\
\text { ECAP + Rolling 2,7 }\end{array}$ & 90 & - & 20 & 10 \\
\hline $\begin{array}{c}\text { Прокатка 1,5 } \\
\text { Rolling 1,5 }\end{array}$ & 560 & 80 & - & - \\
\hline $\begin{array}{c}\text { Прокатка 2,7 } \\
\text { Rolling 2,7 }\end{array}$ & 490 & 10 & 5 & 40 \\
\hline
\end{tabular}


Другой вид имеет структура после предварительной деформации методом РКУП и последующей прокатки (рис. 1e,f). В состоянии «РКУП + Прокатка 1,5» наблюдается практически однородная микроструктура (рис. 1е). Полосы сдвига сохраняются только в отдельных областях, объемная доля полосовой структуры составляет не более $10 \%$. Повышается плотность дислокаций, уменьшается размер структурных элементов как по сравнению с состоянием «РКУП», так и по сравнению с состоянием «Прокатка 1,5» - до 110 нм. В зернах наблюдаются тонкие двойники. Доля зерен, содержащих двойники, увеличивается до $14 \%$. Среднее расстояние между двойниковыми границами уменьшается до 30 нм. Увеличение степени деформации при прокатке после РКУП приводит к формированию однородной зёренно-субзёренной микроструктуры со средним размером зерен 90 нм (рис. 1f). Доля зерен с двойниками возрастает до $20 \%$.

Сравнение микроструктуры стали в разных деформированных состояниях показало, что увеличение степени деформации при прокатке без предварительной деформации РКУП приводит к изменению типа структуры с полосового к равноосному зёренно-субзёренному. При этом размеры структурных элементов практически не изменяются. Применение прокатки после РКУП позволяет дополнительно значительно измельчить микроструктуру. Увеличение степени деформации при прокатке после РКУП не изменяет тип микроструктуры, однако делает ее более однородной и уменьшает размеры зерен дополнительно на $18 \%$.

Изменения микроструктуры при увеличении степени деформации при прокатке влияют на свойства стали. Среднее значение микротвердости стали 08X18Н10Т в состоянии «Закалка» составило $1820 \pm 30 \mathrm{MПа} \mathrm{(рис.} \mathrm{2).}$

В процессе деформации закаленной стали методами РКУП (состояние «РКУП») или прокатки (состояние «Прокатка 1,5») происходит изменение типа структуры: зеренная аустенитная структура трансформируется в полосовую ультрамелкозернистую. В результате в обоих этих состояниях наблюдается значительное повышение микротвердости по сравнению с закаленной сталью. Среднее значение микротвердости стали в состоянии «РКУП» возрастает до $3920 \pm 50$ МПа, т. е. вдвое (рис. 2). Аналогичный уровень микротвердости имеет сталь в состоянии «Прокатка 1,5» (без предварительной обработки РКУП): $3800 \pm 50$ МПа. Близкие значения микротвердости объясняются тем, что в этих двух состояниях формируется подобный тип микроструктуры стали (рис. 1b,c).

Увеличение степени деформации при прокатке от 1,5 до 2,7 приводит к меньшему упрочнению: микротвердость увеличивается дополнительно на 25\% до $4910 \pm 50$ МПа («Прокатка 2,7»), хотя степень деформации возрастает почти вдвое. Прокатка стали после РКУП до степени 1,5 («РКУП + Прокатка 1,5») влечёт за собой аналогичное повышение уровня микротвёрдости на 29\% - до 5040 МПа. В обоих этих случаях наблюдается новое изменение типа структуры от полосового к зёренно-субзёренному (табл. 2, рис. 1).

Дальнейшее увеличение степени деформации при прокатке после РКУП приводит к увеличению микротвердости только на 8\% - до значения $5390 \pm 50$ МПа в состоянии «РКУП + Прокатка 2,7» (рис. 2). Как видно из сравнения рис. 1е и 1f, в этом случае тип структуры не меняется, происходит дальнейшее измельчение размеров зерен/субзерен.

Таким образом, изменение микротвердости аустенитной стали в результате пластической деформации объясняется с позиций классической теории стадийности пластической деформации [16]. На каждом этапе пластической деформации в структуре присутствует два основных типа дислокационной структуры. По мере развития деформации один тип структуры сменяет другой тип. В рассматриваемом случае можно выделить 3 стадии деформации, каждый из которых характеризуется своей величиной упрочнения. На первой стадии происходит трансформация зеренной крупнозернистой структуры в полосовую ультрамелкозернистую. Этот тип структуры наблюдается в состояниях «РКУП» (рис. 1b) и «Прокатка 1,5» (рис. 1с). Эта стадия сопровождается значительным упрочнением: микротвердость возрастает до $100 \%$ (рис. 2). Вторая стадия характеризуется сменой полосовой структуры на зёренно-субзёренную. Такие изменения наблюдаются при увеличении степени прокатки от 1,5 (рис. 1с) до 2,7 (рис. 1d) и при прокатке на степень деформации 1,5 после РКУП (рис. 1е). Этот процесс характеризуется меньшим упрочнением, чем первая стадия - до 25-29\% (рис. 2). После того, как изменение типа структуры произошло, начинается третья стадия деформации, при которой тип структуры не меняется, но происходит дополнительное ее измельчение. Этой стадии соответствует увеличение степени деформации прокаткой после РКУП от 1,5 до 2,7 (сравните рис. 1е и 1f). Микротвердость на этой стадии возрастает только на $8 \%$.

Изменения вида нагружения от РКУП к последующей прокатке позволяет интенсифицировать процесс структурной перестройки за счет активации новых систем скольжения при смене схемы главных напряжений и деформаций $[2,17]$. Это приводит к формированию более мелкозернистой однородной структуры по сравнению с просто прокаткой (без предварительной деформации РКУП). В результате микротвердость стали в состоянии «РКУП + прокатка 1,5» имеет более высокие значения, чем в состоянии «Прокатка 1,5» и даже «Прокатка 2,7».

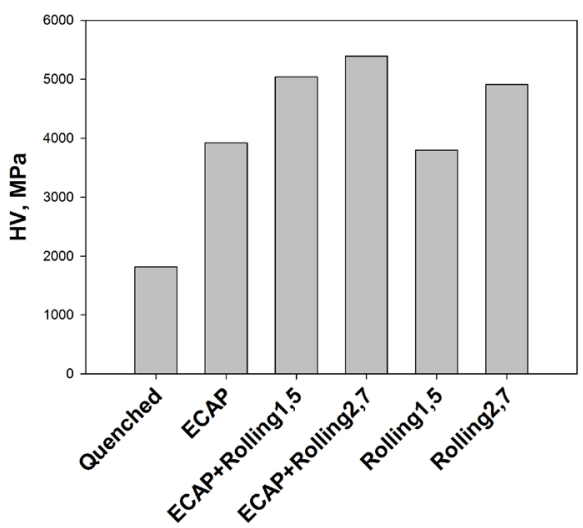

Рис. 2. Микротвердость стали после различной обработки.

Fig. 2. Microhardness of the austenitic steel after different types of processing. 


\section{4. Заключение}

В результате ИПД методом РКУП до 8 проходов аустенитной стали 08X18Н10T происходит формирование микроструктуры преимущественно полосового типа и повышение значения микротвёрдости до 3920 МПа. Прокатка на степень деформации 1,5 крупнозернистого материала приводит к формированию микроструктуры подобного типа с увеличенными размерами структурных элементов, чему соответствует значение микротвёрдости 3800 МПа. Дополнительная прокатка крупнозернистой стали (до степени 2,7) приводит к изменению типа структуры на зёренно-субзёренную, сопровождающемуся повышением микротвёрдости до 4910 МПа.

Прокатка стали после РКУП до степени 1,5 влечёт за собой существенное повышение уровня микротвёрдости до 5040 МПа, обусловленное трансформацией структуры в зёренно-субзёренную. Дальнейшее увеличение степени прокатки после РКУП (до 2,7) не приводит к значительным структурным изменениям и заметному повышению значений микротвердости.

Таким образом, при деформации крупнозернистой аустенитной стали наблюдается три стадии, которые характеризуются разными изменениями структуры и разной величиной упрочнения. На первой стадии крупнозернистая структура трансформируется в ультрамелкозернистую полосовую, что сопровождается увеличением микротвердости в два раза. На второй стадии полосовая структура изменяется в зёренно-субзёренную, что приводит к упрочнению на 25\%. На третьей стадии тип структуры не меняется, но происходит ее дальнейшее измельчение и повышение микротвердости на $8 \%$.

Благодарность/Acknowledgements. Авторь выражают благодарность за поддержку Министерству науки и образования РФ в рамках контракта № 14.583.21.0012 (УИН: RFMEFI58315X0012).

\section{Литература/References}

1. R. Z. Valiev, Y. Estrin, Z. Horita, T.G. Langdon, M. J. Zehenbauer, Y.T. Zhu. Fundamentals of superior properties in bulk nano SPD materials. Mater. Res. Lett., 2016, Vol.4, No 1, pp.1-21.

2. F.Z. Utyashev, G.I. Raab. Deformation methods for obtaining and processing of ultrafine-grained and nanostructured materials. - Ufa: Guillem, Nick Bash. Encyc, 2013, 376 (in Russian) [Ф.3. Утяшев, Г.И. Рааб. Деформационные методы получения и обработки ультрамелкозернистых и наноструктурных материалов. Уфа: Гилем, НИК Башк. энцикл., 2013. - 376.].

3. M. M. Abramova, N. A. Enikeev, R.Z. Valiev, A. Etienne, B. Radiguet, Y. Ivanisenko, X. Sauvage. Grain boundary segregation induced strengthening of an ultrafine-grained austenitic stainless steel. Materials letters 136 (2014), pp. $349-352$.

4. A. V. Ganeev, M. V. Karavaeva, X. Sauvage, E. CourtoisManara, Y. Ivanisenko, R.Z. Valiev. On the nature of high-strength of carbon steel produced by severe plastic deformation. IOP Conf. Series Materials Science and Engineering 63 (2014), 012128. Doi:10.1088/1757899X/63/1/012128.

5. S. V. Dobatkin, O. V. Rybal'chenko, G.I. Raab. Structure formation, phase transformations and properties in $\mathrm{Cr}-\mathrm{Ni}$ austenitic steel after equal-channel angular pressing and heating. Mater. Sci. Eng. A 2007, 463, pp. $41-45$.

6. J.C. Pang, M.X. Yang, G. Yang, S.D. Wu, S.X. Li, Z.F. Zhang. Tensile and fatigue properties of ultrafinegrained low-carbon steel processed by equal channel angular pressing. Mater. Sci.Eng. A 2012, 553, pp. $157-163$.

7. R.Z. Valiev, I.V. Alexandrov. Nanostructured materials produced by severe plastic deformation. M: Logos, 2000, 272 (in Russian) [Валиев Р.3., Александров И. В. Нано структурные материалы, полученные интенсивной пластической деформацией. М: Логос, 2000. 272 с.].

8. Y. Iwahashi, Z. Horita, M. Nemoto, T. G. Langdon. The process of grain refinement in equal-channel angular pressing. Acta mater. Vol.46, 1998, No.9, pp.3317-3331.

9. G. Salischev, R. Zaripova, R. Galeev, O. Valiahmetov. Nanocrystalline structure formation during severe plastic deformation in metals and their deformation behavior. Nanostructured Materials, Vol.6, 1995, pp.913-916.

10. A. Belyakov, K. Tsuzaki, R. Kaibyshev. Nanostructure evolution in an austenitic stainless steel subjected to multiple forging at ambient temperature. Mat. Sci. Forum, Vols. 667 - 669 (2011), pp.553 - 558.

11. A. Polyakov, D. Gunderov, V. Sitdikov, R. Valiev, I. Sevenova, I. Sabirov. Physical Simulation of hot rolling of ultra-fine grained pure titanium. Metall. Trans. B, V.45B, December 2014, pp.2315-2326.

12. N. D. Stepanov, A. V. Kuznetsov, G. A. Salischev, G. I. Raab, R.Z. Valiev. Effect of cold rolling on microstructure and mechanical properties of copper subjected to ECAP with various number of passes. Mat. Sci. and Eng. A 554 (2012), pp. $105-115$.

13. M.Yu. Murashkin, N.A. Enikeev, V.U. Kazykhanov, I. Sabirov, R. Z. Valiev. Physical simulation of cold rolling of ultra-fine grained $\mathrm{Al} 5083$ alloy to study microstructure evolution. Rev. Adv. Mater. Sci. 35 (2013), pp.75-85.

14. S. Sabbaghianrad, T.G. Langdon. Microstructural saturation, hardness stability and superplasticity in ultrafine-grained metals processed by a combination of severe plastic deformation techniques. Letters of materials 5 (3), 2015, pp.335-340.

15. M. V. Karavaeva, M. M. Abramova, N.A. Enikeev, G. I. Raab and R. Z. Valiev. Superior strength of austenitic steel produced by combined processing, including equalchannel angular pressing and rolling. Metals, 2016, 6, 310.

16. N. A. Koneva. Nature of plastic deformation stage. Soros Educational Journal. 1998, № 10, pp. 99 - 105 (in Russian) [Н.А. Конева. Природа стадий пластической деформации. Соросовский образовательный журнал, 1998, № 10, cc. 99 - 105].

17. O. I. Bylja, R. A. Vasin, A. G. Ermachenko, M. V. Karavaeva, A. V. Muravlev, P. V. Chistjakov. The influence of simple and complex loading on structure changes in two-phase titanium alloy. Scripta Materialia Vol.36 (1997), № 8, pp.949-954. 